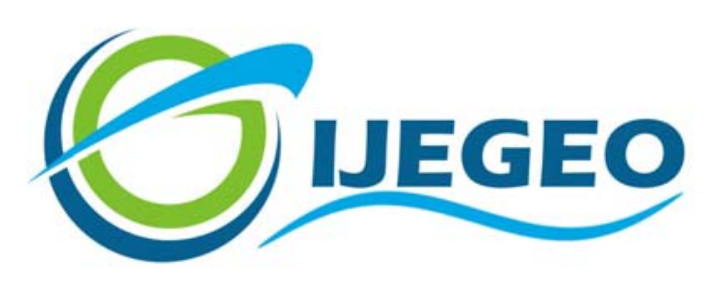

International Journal of Environment and Geoinformatics (IJEGEO) is an international, multidisciplinary, peer reviewed, open access journal.

\title{
Selection of the Most Proper Unmanned Aerial Vehicle for Transportation in Emergency Operations by Using Analytic Hierarchy Process
}

\section{Mustafa ULUKAVAK, Mehmet MIMAN}

\author{
Chief in Editor \\ Prof. Dr. Cem Gazioğlu \\ Co-Editors \\ Prof. Dr. Dursun Zafer Şeker, Prof. Dr. Şinasi Kaya, \\ Prof. Dr. Ayşegül Tanık and Assist. Prof. Dr. Volkan Demir \\ Guest Editor \\ Assoc. Prof. Dr. Nedim Onur Aykut \\ Editorial Committee (January 2021)
}

\begin{abstract}
Assoc. Prof. Dr. Abdullah Aksu (TR), Assit. Prof. Dr. Uğur Algancı (TR), Prof. Dr. Bedri Alpar (TR), Assoc. Prof. Dr. Aslı Aslan (US), Prof. Dr. Levent Bat (TR), Prof. Dr. Paul Bates (UK), İrşad Bayırhan (TR), Prof. Dr. Bülent Bayram (TR), Prof. Dr. Luis M. Botana (ES), Prof. Dr. Nuray Çağlar (TR), Prof. Dr. Sukanta Dash (IN), Dr. Soofia T. Elias (UK), Prof. Dr. A. Evren Erginal (TR), Assoc. Prof. Dr. Cüneyt Erenoğlu (TR), Dr. Dieter Fritsch (DE), Prof. Dr. Çiğdem Göksel (TR), Prof.Dr. Lena Halounova (CZ), Prof. Dr. Manik Kalubarme (IN), Dr. Hakan Kaya (TR), Assist. Prof. Dr. Serkan Kükrer (TR), Assoc. Prof. Dr. Maged Marghany (MY), Prof. Dr. Michael Meadows (ZA), Prof. Dr. Nebiye Musaoğlu (TR), Prof. Dr. Masafumi Nakagawa (JP), Prof. Dr. Hasan Özdemir (TR), Prof. Dr. Chryssy Potsiou (GR), Prof. Dr. Erol Sarı (TR), Prof. Dr. Maria Paradiso (IT), Prof. Dr. Petros Patias (GR), Prof. Dr. Elif Sertel (TR), Prof. Dr. Nüket Sivri (TR), Prof. Dr. Füsun Balık Şanlı (TR), Prof. Dr. Uğur Şanlı (TR), Duygu Ülker (TR), Prof. Dr. Seyfettin Taş (TR), Assoc. Prof. Dr. Ömer Suat Taşkın (TR), Assist. Prof. Dr. Tuba Ünsal (TR), Dr. Manousos Valyrakis (UK), Dr. İnese Varna (LV), Dr. Petra Visser (NL), Prof. Dr. Selma Ünlü (TR), Assoc. Prof. Dr. Oral Yağcı (TR), Prof. Dr. Murat Yakar (TR), Assoc. Prof. Dr. İ. Noyan Yılmaz (AU); Assit. Prof. Dr. Sibel Zeki (TR)
\end{abstract}

Abstracting and Indexing: TR DIZIN, DOAJ, Index Copernicus, OAJ, Scientific Indexing Services, International Scientific Indexing, Journal Factor, Google Scholar, Ulrich's Periodicals Directory, WorldCat, DRJI, ResearchBib, SOBIAD 
Dear colleagues and friends,

International Symposium on Applied Geoinformatics (ISAG2019) was held in Istanbul on 7-9 November 2019. The symposium is organized with the aim of promoting the advancements to explore the latest scientific and technological developments and opportunities in the field of Geoinformatics.

The symposium was jointly organized by the Department of Geomatics Engineering, Yıldız Technical University, Istanbul, Turkey and the Institute of Geodesy and Geoinformatics, University of Latvia, RigaLatvia.

Our main aim was to bring researchers to share knowledge and their expertise about state-of-art developments in the field of Geoinformatics. We wish to discuss the latest developments, opportunities and challenges that can help the Geoinformatics community to solve many real-world challenges. Although this forum is initiated by two countries, Turkey and Latvia, it has a global perspective to promote technologies and advancements that would help us live in a better world.

290 participants and scientists from 27 countries were attended to the ISAG2019. 118 oral and 16 poster presentations were presented by 45 international and 89 Turkish presenters in 29 sessions between 7-9 November 2019.

We are much thankful to our supporting institutions Turkish General Directorate of Mapping, The Embassy of Latvia in Turkey, General Directorate of Geographical Information Systems/Turkey, Fatih Municipality.

The presentation "XXX" was presented at the ISAG2019 and was proposed by our scientific committee for evaluation in the International Journal of Environmental and Geoinformatics (IJEGEO).

The next ISAG symposium will be organized in Riga, Latvia on 16-17 November 2021. I do really hope to see you all in Latvia at the $2^{\text {nd }}$ ISAG Symposium.

On behalf of ISAG-2019 Organization Committee

Conference Chair

Prof. Dr. Bülent Bayram

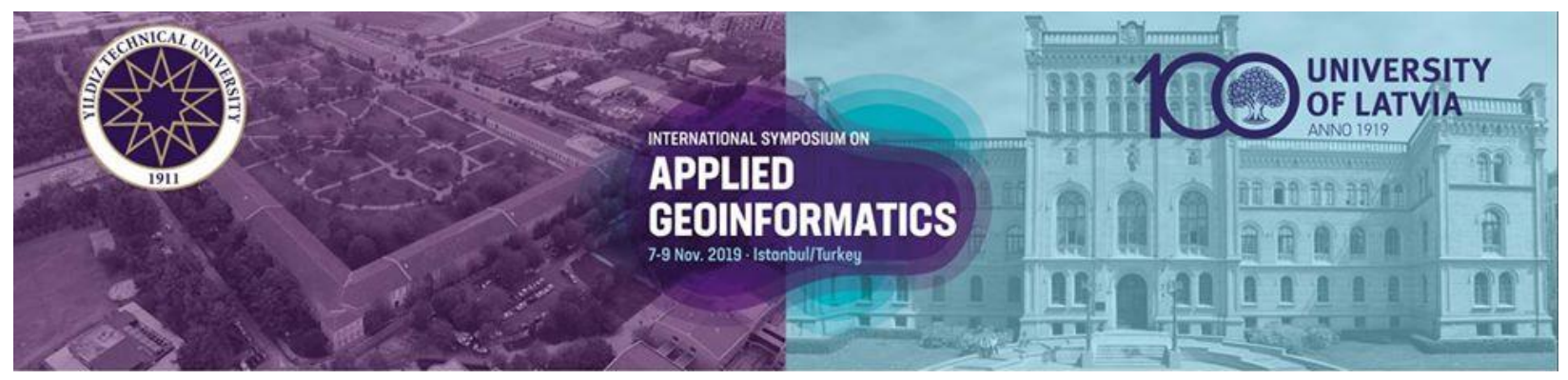


Reaserch Article

\title{
Selection of the Most Proper Unmanned Aerial Vehicle for Transportation in Emergency Operations by Using Analytic Hierarchy Process
}

\author{
Mustafa Ulukavak ${ }^{1, *}$, (iD Mehmet Miman ${ }^{2}$ (iD \\ ${ }^{1}$ Harran University, Faculty of Engineering, Geomatics Engineering, Şanlıurfa, Turkey \\ ${ }^{2}$ Harran University, Faculty of Engineering, Industrial Engineering, Şanlıurfa, Turkey \\ Corresponding author: M. Ulukavak \\ *E-mail: mulukavak@harran.edu.tr
}

Received 30 June 2020

Accepted 30 Nov 2020

How to cite: Ulukavak and Miman (2021). Selection of the Most Proper Unmanned Aerial Vehicle for Transportation in Emergency Operations by Using Analytic Hierarchy Process, International Journal of Environment and Geoinformatics (IJEGEO), 8(1): 078-091, doi: 10.30897/ ijegeo. 760758

\begin{abstract}
Today rapid development on Unmanned Aerial Vehicle (UAV) technologies continues to evolve and expand its use as a tool that can be used in many fields. The most communal areas for the use of UAV are mapping, assessing, and supporting damage assessments, and search and rescue activities, respectively. However, the application of transporting light and important cargoes that have become widespread recently accessing to the difficult areas is also becoming a new sector in the usage areas of UAV. Lightweight, userfriendly designs of UAVs and flight systems managed by automated workflows giving convenience for this field application. In this study, two different flight platforms (3 fixed-wing and 3 multi-rotor) of flight parameters were evaluated by selecting the sales catalog. Brand knowledge of the UAVs has not given into consideration of the belief that it may adversely affect commercial competition. The sample modeled as a multi-criteria decision-making problem consisting of quantitative and qualitative criteria, and the analytic hierarchy process (AHS), which clearly reveals the decision-makers' views for such problems. Priorities for the criteria of each alternative for the payload, UAV weight, maximum altitude, maximum speed, flight time, and controller range criteria with numerical performance values in order to maintain the consistency problem in the AHS method were figured out by direct assignment. The impact of each criterion in the choice and coherence analysis to determine the effect of each alternative criteria were performed using Expert Choice v2000 software. Because of the analysis made, it is seen that multi-rotor UAVs are the predominant choice for fixed-winged UAVs, among which the UAV_4 flight platform is the most appropriate vehicle for emergency transport with an overall weight of 0.2530 . When UAV_4 is compared with other alternative flight platforms, it is seen to be in the foreground according to the criteria of maximum altitude, maximum ground speed, landing field, and ease of use. As seen in the analysis of 2 dimensional alternatives at the end of the example, analysis of UAV to be used in emergency transport according to the landing field and ease of use criteria revealed that multi-rotor UAVs (UAV_4, UAV_5, UAV_6) have more dominant results than fixed-wing UAVs (UAV_1, UAV_2, UAV_3). Although most of the UAV models being developed are still in prototypes, with the rapid development in the field of technology and the industrial knowledge in these applications, further progress can be expected in future projects.
\end{abstract}

Keywords: Unmanned Aerial Vehicle, Emergency Operations, Expert Choice, Analytic Hierarchy Process, Multi-Criteria DecisionMaking

\section{Introduction}

In the twentieth century, remotely controlled air vehicles were not common, but in the twenty-first century, the use of these vehicles flared very quickly. Large-scale unmanned aerial vehicles (UAVs) have been used by various countries for military purposes. Today, the capabilities of the small size of the UAVs have greatly increased and production costs have been significantly reduced. The UAVs have recently been among the most advanced systems in civilian areas of use. Over the past few years, the increase in small-scale UAV applications has become widespread to carry through the needs of more expensive and complex human aircraft systems (Segui-Gasco et al., 2014). This has led to additional investments and a wider market of small UAVs and has resulted in a significant increase compared to costs in UAV (Clarke, 2014; Erenoğlu and Erenoğlu, 2018; Bayırhan and Gazioğlu, 2019;Karataş and Altınışık,
2020; Utlu and Öztürk, 2020). Nowadays, there are three several types of UAV systems produced. These are the fixed-wing, multi-rotor, and hybrid flight platform systems, respectively (Figure 1).

Fixed-wing UAVs (Figure 1a) has a two-wing design and is often used to carry heavy loads. Fixed-wing UAVs is preferred for projects that need to transport cargo over longer distances. They can run in winds up to $50 \mathrm{~km} / \mathrm{h}$ and can usually stay in the air approximately 30 minutes to several hours depending on the model. Most fixed-wing UAV flies with the auto-pilot mode by following pre-determined flight paths that are loaded into the UAV before the flight. The pilot on the ground checks the flight route and makes minor adjustments when necessary and monitors emergency conditions. A significant disadvantage of fixed-wing UAVs is that they usually need the use of an open area (track) for landing and launch. The presence of transportation areas in 
mountainous, dense forests or heavily built environments may also bring some difficulties for UAVs landing and take-offs in terms of transport. Another flight platform used except for fixed-wing flight platforms are also the multi-rotor models (Figure 1b). Multi-rotor UAVs are typically used in shorter flight times and shorter distances to carry lighter loads. The most widely used multi-rotor UAVs have four propellers. So, they are often called quadrocopter. However, one rotor (helicopter) or eight rotors (octocopter) versions are also available. Their main advantage is to be able to vertically take-off and landing and thus they do not need any space for taking off and landing. Many commercial UAVs in small sizes have a battery life of only 10 minutes, while those that can stay in the air for longer periods are significantly more expensive. The third type of the UAV that has just begun to use which is included in the hybrid flight platform (Figure 1c). The hybrid UAVs are new and both wings of the flight platform are equipped with rotors. This configuration eases vertical take-off and landing, and at the same time, it gives the ability to fly horizontally, like fixed-wing UAVs. This structure demonstrates that the UAVs can fly longer distances, which means that it can stay in the air longer times. At the same time, it means that they can carry heavier loads than multi-rotor UAVs.

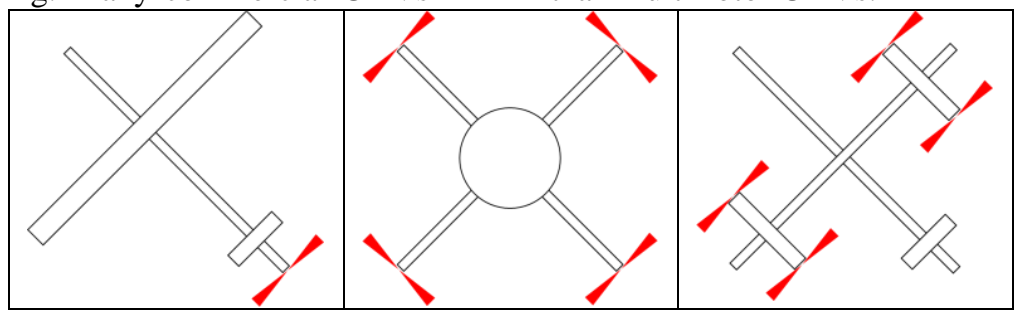

Figure 1. Schematic diagrams of the three different flight platforms

The area's most widespread use of UAVs is mapping (Colomina et al., 2014), supporting and observing damage assessments (Hansen, 2016), search and rescue operations (Waharte et al., 2010) and transporting light and important cargos that have recently become widespread to be delivered to difficult areas, respectively. Nowadays, mapping applications are at the forefront of the most common and popular uses of UAVs. Lightweight, user-friendly, affordable design and automated workflows, which makes this technology accessible even for non-technical users. Mapping UAVs are used with high accuracy to create two-dimensional maps, elevation models and 3D terrain models. Another area of use of the UAV after assessment of damage occurring disaster, evaluation, and observation of the change process. As an example, after the Sandy Hurricane disaster in Haiti in 2012, UAVs have been used to assess the damage caused by floods more quickly than the damage detection work that can be done with satellite imagery (Luege, 2016). Another area of use of UAVs is in support of search and rescue operations. A multi-purpose UAV design has been made that can be used in search and rescue operations in case of a possible avalanche that may occur in the mountains and can fly at high altitudes and with strong winds at low temperatures (Silvagni et al., 2017). The availability of this flight platform equipped with a thermal camera to support search and rescue activities has been reviewed in detail. Another application area is the cargo dispatching, which has recently become widespread with pilot projects and will be supported in the future by the transport sector. These small vehicles have quicker and easier results in reaching the hard, dirty, and dangerous areas that are difficult for people to access. While most developing models are still being prototypes, along with the recent rapid developments and industry interest in this application, further progress can be expected from this technology in the coming years (FSD, 2016). UAVs' lightweight, user-friendly design and flight systems managed with automated workflows, providing opportunities for different applications in many areas, even for non-expert users in this area. For their ease of use, UAV systems are gaining a rapidly evolving character as a complement to traditional air transport vehicles, offering options such as delivering cargoes with these systems and transporting small commodities. Most developing cargo-UAV models are still prototypes, but pilot projects are now limited to their use in transporting lightweight and high-value products. This study was modelled as a multi-criteria decision problem for appropriate selection of delivery in emergency situations by using UAVs.

As well as cargo transportation, in the context of emergency such as unexpected earthquakes, accidents, military operations, S.O.S request from mountaineers it is important to supply crucial materials to the site which may not be easily accessible timely manner through the conventional methods. To address this problem UAVs are considered through expert opinion-based methodology (AHP) to exploit the best alternative transportation mode of such materials. Hence, the gap in the associated literature will be filled via this research effort.

The study continues with materials and methodology, the implementation of the multi-criteria decision support system with ExpertChoice v2000 software, the results, and finally the discussion section. Fixed-wing UAVs (Figure 1a) has a two-wing design The area's most widespread use of UAVs is mapping (Colomina et al., 2014), supporting and observing damage assessments (Hansen, 2016), search and rescue operations (Waharte et al., 2010), and transporting light and important cargos that have recently become widespread to be delivered to difficult areas, respectively. Nowadays, mapping applications are at the forefront of the most common and popular uses of UAVs. Lightweight, user-friendly, affordable design, and automated workflows, which makes this technology accessible even for non-technical 
users. Mapping UAVs are used with high accuracy to create two-dimensional maps, elevation models, and 3D terrain models. Another area of use of the UAV after assessment of damage occurring disaster, evaluation, and observation of the change process. As an example, after the Sandy Hurricane disaster in Haiti in 2012, UAVs have been used to assess the damage caused by floods more quickly than the damage detection work that can be done with satellite imagery (Luege, 2016). Another area of use of UAVs is in support of search and rescue operations. A multi-purpose UAV design has been made that can be used in search and rescue operations in case of a possible avalanche that may occur in the mountains and can fly at high altitudes and with strong winds at low temperatures (Silvagni et al., 2017). The availability of this flight platform equipped with a thermal camera to support search and rescue activities has been reviewed in detail. Another application area is cargo dispatching, which has recently become widespread with pilot projects and will be supported in the future by the transport sector. These small vehicles have quicker and easier results in reaching the hard, dirty, and dangerous areas that are difficult for people to access. While most developing models are still being prototypes, along with the recent rapid developments and industry interest in this application, further progress can be expected from this technology in the coming years (FSD, 2016). UAVs' lightweight, user-friendly design and flight systems managed with automated workflows, providing opportunities for different applications in many areas, even for non-expert users in this area. For their ease of use, UAV systems are gaining a rapidly evolving character as a complement to traditional air transport vehicles, offering options such as delivering cargoes with these systems and transporting small commodities. Most developing cargo-UAV models are still prototypes, but pilot projects are now limited to their use in transporting lightweight and high-value products. This study was modeled as a multi-criteria decision problem for appropriate selection of delivery in emergencies by using UAVs.

\section{Materials and Methods \\ Tools and parameters used in the study.}

As the areas of use of UAVs become widespread, many of the features of flight platforms need to be known to be able to benefit from them at the optimum level. The focus of this research is Class I UAVs (in Europe less than $50 \mathrm{lbs}$, in the US less than $25 \mathrm{lbs})$. The characteristics of the UAVs that can be used in the applications to be carried out based on cargo transportation can be listed as follows; payload, UAV weight, maximum altitude, maximum ground speed, approximate flight time, remote controller range, landing field needs, and ease of use, respectively. The payload is defined as the maximum amount of weight that can be carried by UAV and the unit of the payload is gram (Eisenbeiss, 2009; Herwitz et al., 2002). The load to be transported is included in the flight parameters of the UAV. If the load weight of the UAV is too heavy to be carried, this will shorten its battery life, and it will also cause possible damage to the carrier part of the UAV.
Another parameter that is used together with the payload is the weight of the UAV (Thamm et al., 2006). The weight of the UAV is referred to as the total weight of the flight equipment excluding the payload of the UAV and the unit of UAV weight is the gram. Within this parameter, there are many flight parts such as the mainframe of UAV, carrier parts, electronic control units, control systems, batteries, motors, connection equipment, propellers, wings, etc. (Eisenbeiss, 2009). One of the important parameters for the UAVs is the maximum altitude that the UAV can reach (van Blyenburgh, 1999). Take-off and landing times of the UAV is to be considered to carry equipment weather and atmospheric conditions (temperature, wind, air pressure, humidity, etc.) is considered as one of the most important factors influencing these variables. In addition to the maximum altitude, maximum ground speed is also among the parameters that should be included in the applications that can be done with UAV. The maximum ground speed is the maximum speed that the UAV can reach with the payload within the permitted limits and is expressed in meters per second $(\mathrm{m} / \mathrm{s})$. The battery capacity of the UAV, payload, and atmospheric weather conditions can be considered one of the most important factors affecting the maximum ground speed of the UAV. Approximate flight time refers to the flight time that the UAV will be able to travel at a certain altitude with the amount of payload, flight equipment, and optimum speed. The unit of the approximate flight time is minute. Atmospheric weather conditions can also affect the duration of the flight time. Another most important feature of the UAV is considered as the remote-controller range ( $\mathrm{RC}$ range). The remotecontroller range is referred to as the maximum distance that the UAV can be navigated in the remote-control domain (FAA, 2016). The RC range is a parameter that can be affected by various variables depending on the natural or artificial shapes of the terrain that can be interruptive with the remote-control signals of the UAV, the battery level of the remote controller device, the flight altitude, and the magnetic activities that can occur in the flight environment. The unit of the $\mathrm{RC}$ range in meters. One of the most important parameters that are necessary to the start and the finish of the flight of the UAV is also known as the needs of the landing field. The landing field needed for take-off and landing of UAVs is the place that is required for a specific length or safe departure. Landing field needs for fixed-wing UAVs are required insistently whereas, during take-off and landing of multi-rotor UAV is much less important for this parameter. The last parameter used in this study is the ease of use of UAVs. Instantaneous image transfer to the ground station, aerodynamics, ability to maneuver easily in the air, and advantages provided by the operator for re-landing are the criteria that can be included in this parameter. In this context, ease of use is said to be the ability of the navigational commands sent via the remote-control device by the operator to be managed without requiring extra intervention under the optimum atmospheric weather conditions for flight. In this study, six different models of fixed-winged and multi-rotor types of two different flight platforms were randomly selected and flight parameters were evaluated for cargo 
transportation. Brand knowledge of UAVs is not taken into account in the assessment that they may adversely affect commercial competition. The specifications of the fixed-wing and multi-rotor UAVs used in the study are given in Table 1 and the images of the UAVs are given in Figure 2.

Table 1. Parameters of UAV with fixed-wing and multi-rotor

\begin{tabular}{|c|c|c|c|c|c|c|c|c|c|}
\hline$\frac{\bar{d}}{\tilde{g}}$ & 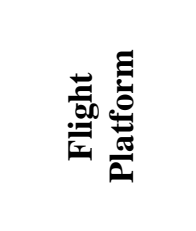 & 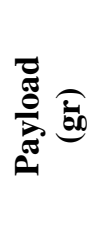 & 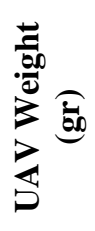 & 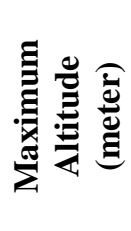 & 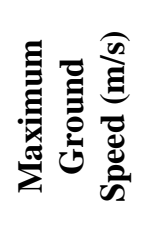 & 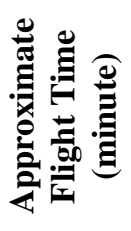 & 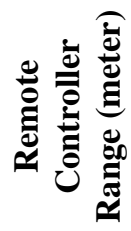 & 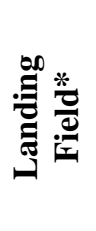 & 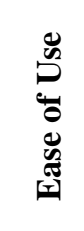 \\
\hline UAV_1 & Fixed-Wing & 1500 & 2000 & 250 & 20 & 60 & 2000 & + & Hard \\
\hline UAV_2 & Fixed- Wing & 500 & 2500 & 200 & 18 & 60 & 2000 & + & Hard \\
\hline UAV_3 & Fixed- Wing & 1000 & 2500 & 250 & 20 & 45 & 2000 & + & Hard \\
\hline UAV_4 & Multi-Rotor & 3000 & 6000 & 250 & 36 & 30 & 2000 & - & Easy \\
\hline UAV_5 & Multi-Rotor & 8000 & 5400 & 250 & 22 & 45 & 15000 & - & Easy \\
\hline UAV_6 & Multi-Rotor & 5000 & 6000 & 250 & 17 & 45 & 4000 & - & Easy \\
\hline
\end{tabular}

*(+) necessary, (-) unnecessary

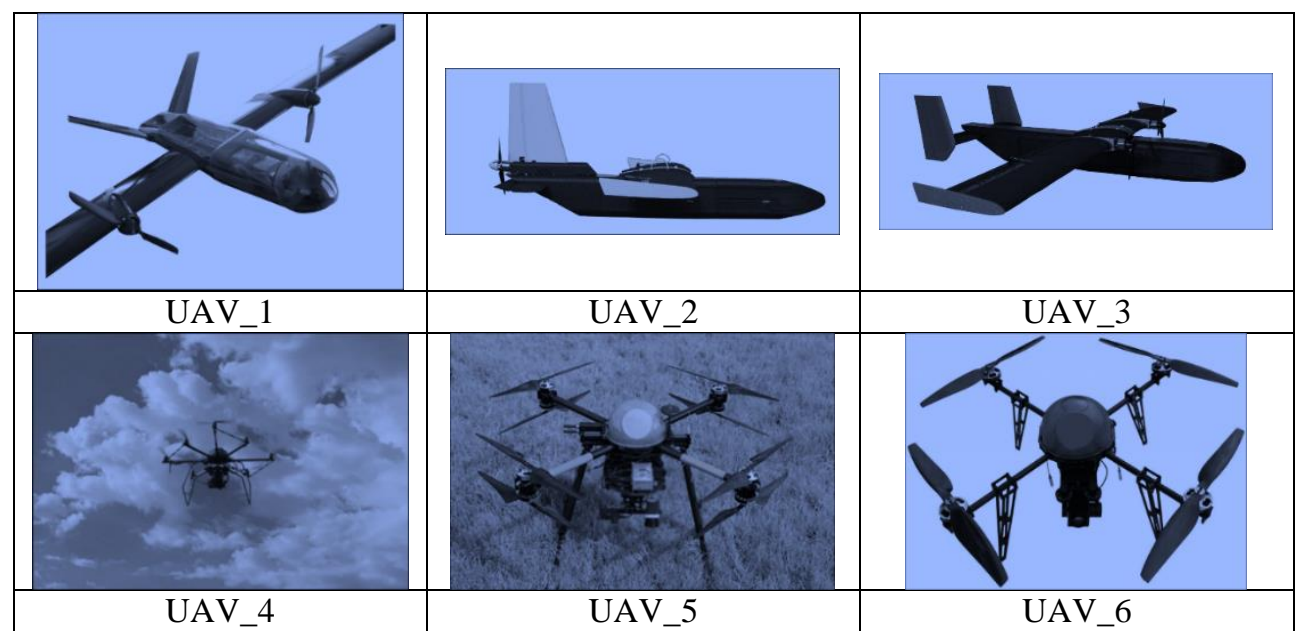

Figure 2. Alternative UAV vehicles for transportation

These alternatives were taken into consideration because of their common usage and widespread availability in markets rather than helicopters which do not appear convenient vehicles for the site with limited accessibility and have noticeably short time usage in air. Moreover, quadrotors provide the great amount of safe flights due to their available rotors.

\section{Analytic Hierarchy Process}

The most proper UAV selection for transportation in emergency whose parameters provided above was modeled as a multi-criteria decision making problem that consists of qualitative and quantitative criteria and its solution was pointed out through Analytic Hierarchy Process (AHP), which is known to be one of the most used techniques that incorporate with the decisionmaker' opinion explicitly. Analytic hierarchy process determines the alternatives' relative standing on the ratio scale basis and reflects the decision maker's intuitive comparisons with corresponding consistency in their judgments (Al-Harbi, 2001). At each level in the hierarchy, the decision-maker makes pairwise comparisons for the elements at that level with regards to preceding levels of criteria and synthesizes the judgments through different levels to estimate each alternative's impact on the overall goal of the hierarchy (Kablan, 2004). In the literature, AHP has been used often with a broad range of applications as a multicriteria decision-making technique. Among its applications, there are a variety of fields such as determination of energy politics (Elkarmi et al., 1993), project management (Enyinda, 2017), evaluation of manufacturing technologies (Al-Ahmari, 2008), selection of manufacturing process (Tiwari et al., 2001), forming teams (Zakarian et al., 1999), selection of marriage partner (Hajeeh et al., 2009), performance management (Mizrahi, 2017) and health care systems (Schmidt et al., 2015; Khorrami, et al., 2018).

Three basic steps of AHP can be summarized as $i$ ) making pairwise judgments to obtain the comparison matrix $i$ ) determination of local weights aggregation of which constitute to final weights of alternatives iii) checking for consistency of comparisons at each level and all-through the global hierarchy. Elements at a particular level are compared pairwise with regard to 
immediate upper level as quantitative or qualitative judgments to reflect the decision maker's opinion in the AHP (T L Saaty, 2006). This comparison is conducted generally through a 9-point scale listed in Table 2 (Thomas L. Saaty, 1990).

Table 2. Basic comparison scale for pairwise judgments (Thomas L. Saaty, 1990)

\begin{tabular}{lll}
\hline \hline Absolute Scale & Definition & Explanation \\
\hline \hline 1 & Equal importance & $\begin{array}{l}\text { Two activities contribute equally to the objective. } \\
\text { another }\end{array}$ \\
\hline 5 & Essential or strong importance & $\begin{array}{l}\text { Experience and judgment strongly favor one activity over } \\
\text { another. }\end{array}$ \\
\hline 7 & Very strong importance & $\begin{array}{l}\text { Activity is strongly favored, and its dominance is demonstrated } \\
\text { in practice. }\end{array}$ \\
\hline 9 & Extreme importance & $\begin{array}{l}\text { The evidence favoring one activity over another is of the } \\
\text { highest possible order of affirmation. }\end{array}$ \\
\hline $2,4,6,8$ & Intermediate values between two adjacent judgments \\
\hline Reciprocals & $\begin{array}{l}\text { If activity } i \text { has one of the above numbers assigned to it when compared with activity } j, \text { then } j \text { has the } \\
\text { reciprocal value when compared with } i .\end{array}$ \\
\hline \hline
\end{tabular}

AHP first determines the relative weights of criteria in a top-down fashion and progresses towards alternatives by computing priority weights of elements at each level ending up the priority weights of alternatives through aggregation bottom-up style at a time (Stam et al., 2003). Saaty, (1988) presents priority weights associated with a pairwise comparison matrix as a prime eigenvector and normalizing the components of the prime eigenvector to provide a unique solution. Let $\mathbf{A}$ be an $m \times m$ comparison matrix for $m$ evaluation criteria and $a_{j k}$ the entry of $\mathbf{A}$ represents the relative importance of the $j^{\text {th }}$ criterion with respect to the $k^{\text {th }}$ criterion. Each of the $\bar{a}_{j k}$ entry in the normalized pairwise comparison matrix $\mathbf{A}_{\text {norm }}$ corresponds to the component in the $j^{\text {th }}$ row and $k^{\text {th }}$ column and computed according to Eq. (1).

$\bar{a}_{j k}=\frac{a_{j k}}{\sum_{l=1}^{m} a_{l k}}$

Each $w_{j}$ the entry of $m$-column criteria weights vector $\boldsymbol{w}$ is obtained according to (2) by averaging all entries of each row in $\mathbf{A}_{\text {norm }}$.

$w_{j}=\frac{\sum_{k=1}^{m} \bar{a}_{j k}}{m}$

After preference information corresponding comparison matrices at each level is obtained locally, this information is aggregated layer by layer in a bottom-up fashion to obtain global priority weights (scores) of alternatives in consideration. In a multicriteria decision making problem with $n$ alternatives and, $m$ criteria (options), let $\mathbf{S}$ be an $n \times m$ choice score matrix. The $s_{i j}$ the entry of $\mathbf{S}$ is a component that shows $i$ th choice (alternative)' score with respect $j^{\text {th }}$ criterion. Assume $\mathbf{B}^{(j)}$ is an $n \times n$ pairwise comparison matrix of $n$ choices (alternatives) according to $j^{\text {th }}$ criterion, the same two steps procedure (first normalization, i.e. dividing of each entry by the sum of entries in the corresponding column; second obtaining the weight vector, i.e. averaging entries of each row) applied to pairwise comparison matrix $\mathbf{A}$ is also applied to each $\mathbf{B}^{(j)}(j=1, \ldots, m)$ of $m$ criteria, and score vectors of $\boldsymbol{s}^{(j)}(j=1, \ldots, m)$ are obtained. The score matrix $\mathbf{S}$, is consisting of $\boldsymbol{s}^{(j)}$ corresponding to the $j^{\text {th }}$ column according to eq. (3) that shows the scores of alternatives (choices) according to the $j^{\text {th }}$ criterion.

$\boldsymbol{S}=\left[\begin{array}{lll}\boldsymbol{S}^{(1)} & \ldots & \boldsymbol{S}^{(m)}\end{array}\right]$

$n$-column global scores (priority weights) vector $\boldsymbol{v}$ is obtained through the multiplication of $\mathbf{S}$ and $\boldsymbol{w}$ according to eq. (4). The $i^{\text {th }}$ component of, $v_{i}$, shows the global score assigned to $i^{\text {th }}$ alternative by the AHP.

$v=\mathbf{S} . \boldsymbol{w}$

The ranking of alternatives (choices) is accomplished by ordering them according to their global scores in a descending scheme.

The consistency of the decision maker's pairwise comparative evaluations in each judgment (comparison) matrix is checked by the AHP through consistency ratio $C R$ according to Eq. (5).

$C R=\frac{C I}{R I}$

$C I$ is the consistency index of an $n \times n$ judgment matrix using its eigenvector $\lambda_{\max }$ through Eq. (6).

$C I=\frac{\lambda_{\max }-n}{n-1}$

In practice, $\lambda_{\max }$ can be approximated by averaging elements of the vector whose $j^{\text {th }}$ component is the ratio of the $j^{\text {th }}$ element of $\mathbf{A} \cdot \boldsymbol{w}$ to the $j^{\text {th }}$ element of $\boldsymbol{w}$.

$R I$ is the random index where all entries of $\mathbf{A}$ are random and obtained averaging CIs corresponding to randomly obtained pairwise judgment matrices, As. RI values reported and used by Lee (2017) according to Saaty and Vargas (2000) and Saaty (2005) for $n \leq 15$ are tabulated in Table 3. 
Table 3. Random Indices (Saaty and Vargas, 2000. Saaty, 2005)

\begin{tabular}{|c|c|c|c|c|c|c|c|c|c|c|c|c|c|c|c|}
\hline$n$ & 1 & 2 & 3 & 4 & 5 & 6 & 7 & 8 & 9 & 10 & 11 & 12 & 13 & 14 & 15 \\
\hline$R I$ & 0.00 & 0.00 & 0.58 & 0.90 & 1.12 & 1.24 & 1.32 & 1.41 & 1.45 & 1.49 & 1.51 & 1.54 & 1.56 & 1.57 & 1.58 \\
\hline
\end{tabular}

The global consistency of hierarchical structure is determined by the global consistency ratio $C R H$ applied to all through the hierarchy in a similar fashion (the ratio of aggregated consistency index computed for overall hierarchy, $M$, to aggregated random index computed for overall hierarchy, $\bar{M}$ ). For a hierarchical structure with three levels of $M$ and $\bar{M}$ are computed through eq. (7) and eq. (8) respectively as an illustration.

$M=$ second level $C I+\left|\begin{array}{c}\text { second - level } \\ \text { priority weights } \\ \text { vector }\end{array}\right| \times\left|\begin{array}{c}\text { third }- \text { level } \\ C I \text { s } \\ \text { vector }\end{array}\right|$

$\bar{M}=$ second level $R I+\left|\begin{array}{c}\text { second - level } \\ \text { priority weights } \\ \text { vector }\end{array}\right| \times\left|\begin{array}{c}\text { third }- \text { level } \\ R I \text { s } \\ \text { vector }\end{array}\right|$

$C R H=\frac{M}{\bar{M}}$

For each level at the hierarchy, the consistency of the structure can be similarly computed bottom-up fashion. For a global hierarchy as well as a single judgment matrix, it is a common application to assume an acceptable level of consistency for $C R$ and $C R H$ having a value equal to or less than 0.1 (Schmidt et al., 2015).

\section{Applications and Results}

The research structure of this study is explanatory and explorative as it increases the knowledge about the selection of the best UAV for transportation in emergencies. Therefore, it takes a significant place to gather information about relevant key parameters and evaluate each UAV option in terms of each parameter. Here, the purpose is to use the AHP which known to work well for qualitative criteria as a multicriteria decision-making technique in order to determine key characteristics of a UAV for transportation in emergency and to improve foresight and insights for transporting medicine in an emergency as providing transparency of analysis of such cases. The steps of the application of the AHP used in this study is demonstrated in Figure 3. First of all, the problem in a hierarchy of transportation with the selection of the most proper UAV in emergency was determined by identifying criteria and alternatives. Later, criteria were subjected to pairwise comparison evaluations till the consistency ratio becomes less than 0.1 to obtain local priority weights of criteria. After that, depending on whether performance data of each UAV is available for a criterion, either direct assessment based on performances or pairwise judgments of alternatives based on an expert opinion, the local priority weights of alternatives for each criterion were determined along with associated consistency ratio of less than 0.1 . Aggregating local weights in a bottom-up fashion, the global weight of each alternative is obtained leading to the preferability ratio of them. Finally, the effect of each criterion on the best choice as well as the impact of each criterion on alternatives were analyzed through sensitivity analysis conducted through the Expert Choice v2000 software.

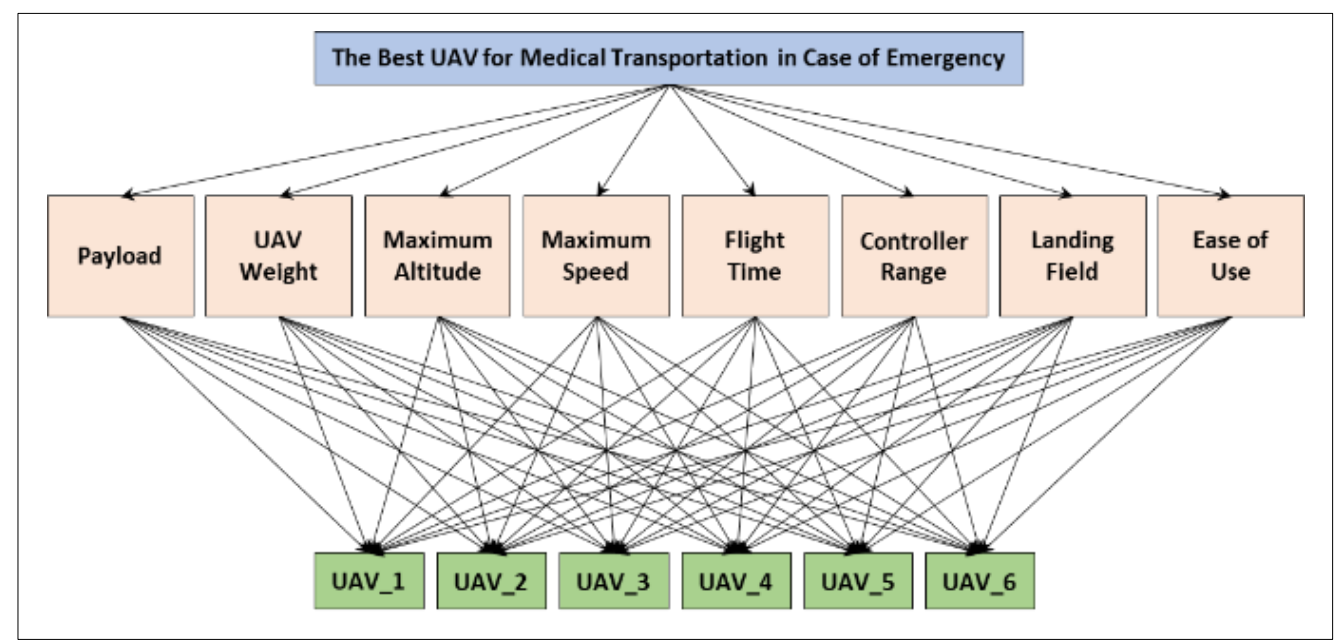

Figure 3. The AHP's Hierarchical Structure 
Figure 4. Steps of The AHP

The Determination of The Importance of Criteria

To determine local weights of criteria, one of the above AHP steps, a pairwise comparison matrix with consistency ratio was constructed based on an expert opinion as provided in Table 4. According to this, for transporting medicine in an emergency with a UAV, landing field and ease of use appear to be the most effective criteria for the selection of the best UAV.

Table 4. Obtaining Priority Weights for the Criteria

The Most Appropriate UAV Selection for Medical Transportation in Emergencies

\begin{tabular}{|c|c|c|c|c|c|c|c|c|c|}
\hline \multirow[b]{2}{*}{ Criterion 1} & \multicolumn{8}{|c|}{ Criterion 2} & \multirow{2}{*}{$\begin{array}{l}\text { Priority } \\
\text { Weight }\end{array}$} \\
\hline & Payload & $\begin{array}{c}\text { UAV } \\
\text { Weight }\end{array}$ & $\begin{array}{c}\text { Maximum } \\
\text { Altitude }\end{array}$ & $\begin{array}{l}\text { Maximum } \\
\text { Speed }\end{array}$ & $\begin{array}{l}\text { Flight } \\
\text { Time }\end{array}$ & $\begin{array}{c}\text { Controller } \\
\text { Range }\end{array}$ & $\begin{array}{l}\text { Landing } \\
\text { Field }\end{array}$ & $\begin{array}{c}\text { Ease } \\
\text { of Use }\end{array}$ & \\
\hline Payload & 1 & 2 & $1 / 2$ & $1 / 5$ & $1 / 2$ & $1 / 5$ & $1 / 8$ & $1 / 8$ & 0.031 \\
\hline UAV Weight & & 1 & $1 / 2$ & $1 / 5$ & $1 / 5$ & $1 / 4$ & $1 / 7$ & $1 / 5$ & 0.027 \\
\hline Maximum Altitude & & & 1 & $1 / 3$ & $1 / 3$ & $1 / 2$ & $1 / 5$ & $1 / 5$ & 0.047 \\
\hline Maximum Speed & & & & 1 & 1 & $1 / 2$ & $1 / 5$ & $1 / 5$ & 0.092 \\
\hline Flight Time & & & & & 1 & $1 / 2$ & $1 / 5$ & $1 / 5$ & 0.081 \\
\hline Controller Range & & & & & & 1 & $1 / 5$ & 1 & 0.133 \\
\hline Landing Field & & & & & & & 1 & 2 & 0.353 \\
\hline Ease of Use & & & & & & & & 1 & 0.236 \\
\hline
\end{tabular}

Determination of State of Alternatives for Each Criterion

In order not to encounter consistency problem in the AHP method, for the criteria that have quantitative performance measures such as payload, UAV weight, maximum altitude, maximum speed, flight time, and controller range, each alternative's priority weight with respect to each criterion was determined according to direct assessment (Table 5). Here, for criteria where higher performance value is more preferable, such as payload, maximum altitude, maximum ground speed, approximate flight time, and remote controller range, options' (alternatives') priority weights were determined through linear normalization as described below. If alternative $i$ 's performance value is $p_{i}$, the associated priority weight $c_{i}$ is obtained by the ratio of $i^{\text {th }}$ performance value to the sum of all performance values according to Eq. (10). 
$c_{i}=\frac{p_{i}}{\sum_{l=1}^{m} p_{i}}$

If the smaller performance value is more preferable for a criterion such as (UAV weight), then normalization is performed for $p_{i}^{\prime}$ values, that are intermediate computational values obtained through the division of the best performance value (the smallest value) by each performance value, $p_{i}$ according to Eq. (11). $p_{i}^{\prime}=\frac{\min _{i}\left\{p_{i}\right\}}{p_{i}}$

The computational results of the above operations were presented in Table 5 for the criteria of payload, UAV weight, maximum altitude, maximum speed, flight time, and controller range.

Table 5. Priority Weights of Alternatives for Criteria based on Performance Measures

\begin{tabular}{ccccccc}
\hline \hline & \multicolumn{3}{c}{ Priority Weights } \\
\cline { 2 - 7 } Alternative & Payload & $\begin{array}{c}\text { UAV } \\
\text { Weight }\end{array}$ & $\begin{array}{c}\text { Maximum } \\
\text { Altitude }\end{array}$ & $\begin{array}{c}\text { Maximum } \\
\text { Speed }\end{array}$ & $\begin{array}{c}\text { Flight } \\
\text { Time }\end{array}$ & $\begin{array}{c}\text { Controller } \\
\text { Range }\end{array}$ \\
\hline UAV_1 & 0.0789 & 0.2749 & 0.1724 & 0.1504 & 0.2105 & 0.0741 \\
UAV_2 & 0.0263 & 0.2200 & 0.1379 & 0.1353 & 0.2105 & 0.0741 \\
UAV_3 & 0.0526 & 0.2200 & 0.1724 & 0.1504 & 0.1579 & 0.0741 \\
UAV_4 & 0.1579 & 0.0916 & 0.1724 & 0.2707 & 0.1053 & 0.0741 \\
UAV_5 & 0.4211 & 0.1018 & 0.1724 & 0.1654 & 0.1579 & 0.5556 \\
UAV_6 & 0.2632 & 0.0916 & 0.1724 & 0.1278 & 0.1579 & 0.1481 \\
\hline \hline
\end{tabular}

Priority weights for qualitative criteria such as landing field and ease of use were obtained based on a pairwise comparison matrix through an expert opinion with corresponding consistency ratios and tabulated in Table
6. The local weights of criteria as well as local weights of alternatives for each criterion along with global weights of them through aggregation with corresponding consistency ratio are presented in Table 7.

Table 6. Priority Weights of Alternatives for Criteria based on Pairwise Comparison Matrices

\section{Comparison of Alternative according to Landing Field}

\begin{tabular}{|c|c|c|c|c|c|c|c|}
\hline \multirow[b]{2}{*}{ Alternative 1} & \multicolumn{6}{|c|}{ Alternative 2} & \multirow{2}{*}{$\begin{array}{c}\text { Priority } \\
\text { Weight }\end{array}$} \\
\hline & UAV_1 & UAV_2 & UAV_3 & UAV_4 & UAV_5 & UAV_6 & \\
\hline UAV_1 & 1 & 5 & 2 & $1 / 7$ & $1 / 7$ & $1 / 7$ & 0.065 \\
\hline UAV_2 & & 1 & $1 / 2$ & $1 / 7$ & $1 / 7$ & $1 / 7$ & 0.029 \\
\hline UAV_3 & & & 1 & $1 / 7$ & $1 / 7$ & $1 / 7$ & 0.040 \\
\hline UAV_4 & & & & 1 & 2 & 1 & 0.318 \\
\hline UAV_5 & & & & & 1 & $1 / 2$ & 0.232 \\
\hline UAV_6 & & & & & & 1 & 0.318 \\
\hline
\end{tabular}

$\mathrm{CR}=0.06$

Comparison of Alternative according to Ease of Use

Alternative 2

\begin{tabular}{ccccccccc} 
& \multicolumn{7}{c}{ Alternative 2 } & Priority \\
Alternative 1 & UAV_1 & UAV_2 & UAV_3 & UAV_4 & UAV_5 & UAV_6 & Weight \\
\hline UAV_1 & 1 & 2 & 1 & $1 / 5$ & $1 / 5$ & $1 / 5$ & $\mathbf{0 . 0 5 8}$ \\
UAV_2 & & 1 & $1 / 2$ & $1 / 7$ & $1 / 7$ & $1 / 7$ & $\mathbf{0 . 0 3 5}$ \\
UAV_3 & & & 1 & $1 / 5$ & $1 / 5$ & $1 / 5$ & $\mathbf{0 . 0 5 8}$ \\
UAV_4 & & & & 1 & 2 & 2 & $\mathbf{0 . 3 5 2}$ \\
UAV_5 & & & & & 1 & $1 / 2$ & $\mathbf{0 . 2 2 0}$ \\
UAV_6 & & & & & & 1 & $\mathbf{0 . 2 7 8}$ \\
\hline
\end{tabular}

$\mathrm{CR}=0.03$ 
Table 7. Evaluation of Alternatives

\begin{tabular}{|c|c|c|c|c|c|c|c|c|c|c|}
\hline \multirow{2}{*}{$w_{\mathrm{j}}$} & \multirow{2}{*}{ ATTRIBUTES } & \multicolumn{6}{|c|}{ UAV TYPE-weights } & \multirow{2}{*}{$C I^{*}$} & \multirow{2}{*}{$R I^{*}$} & \multirow{2}{*}{$C R^{*}$} \\
\hline & & UAV_1 & UAV_2 & UAV_3 & UAV_4 & UAV_5 & UAV_6 & & & \\
\hline 0.0310 & Payload & 0.0789 & 0.0263 & 0.0526 & 0.1579 & 0.4211 & 0.2632 & 0.00 & 1.24 & 0.00 \\
\hline 0.0270 & UAV Weight & 0.2749 & 0.2200 & 0.2200 & 0.0916 & 0.1018 & 0.0916 & 0.00 & 1.24 & 0.00 \\
\hline 0.0470 & Maximum Altitude & 0.1724 & 0.1379 & 0.1724 & 0.1724 & 0.1724 & 0.1724 & 0.00 & 1.24 & 0.00 \\
\hline 0.0920 & Maximum Ground Speed & 0.1504 & 0.1353 & 0.1504 & 0.2707 & 0.1654 & 0.1278 & 0.00 & 1.24 & 0.00 \\
\hline 0.0810 & Approximate Flight Time & 0.2105 & 0.2105 & 0.1579 & 0.1053 & 0.1579 & 0.1579 & 0.00 & 1.24 & 0.00 \\
\hline 0.1330 & Remote Controller Range & 0.0741 & 0.0741 & 0.0741 & 0.0741 & 0.5556 & 0.1481 & 0.00 & 1.24 & 0.00 \\
\hline 0.3530 & Landing Field & 0.0650 & 0.0290 & 0.0400 & 0.3180 & 0.2320 & 0.3180 & 0.07 & 1.24 & 0.06 \\
\hline 0.2360 & Ease of Use & 0.0580 & 0.0350 & 0.0580 & 0.3520 & 0.2200 & 0.2780 & 0.04 & 1.24 & 0.03 \\
\hline & Overall (Global) & 0.1070 & 0.0820 & 0.0890 & 0.2530 & 0.2330 & 0.2360 & 0.12 & 2.65 & 0.05 \\
\hline
\end{tabular}

According to Table 7, rotor-wing UAVs dominate fixedwing UAVs in terms of preferability, and among UAV_4 flight platform appears to be the most suitable vehicle for transporting medicine in emergencies with its global weight of 0.2530 . UAV_4 comes forward to be the first option compared with other alternative flight platforms when maximum altitude, maximum ground speed, landing field, and ease of use criteria are considered. The global consistency of hierarchy, as well as all comparison matrix $(\mathrm{CRH}=0.05)$, was found to be less than 0.1 , thus is at the acceptable level.

\section{Sensitivity Analysis}

For the sensitivity analysis that shows how much the result obtained applies and robust to the problem parameters (Ossadnik et al., 2013), ExpertChoice v2000 was utilized. ExpertChoice enables users to specify the variations in criteria as input data for analysis through its user-friendly and interactive interface and presents the impacts of changes as enriched images (Ishizaka et al., 2011). The overall synthesized results and weights of alternatives with the weights of criteria are demonstrated in Figure 5 and Figure 6 respectively in the ideal model for the solution.

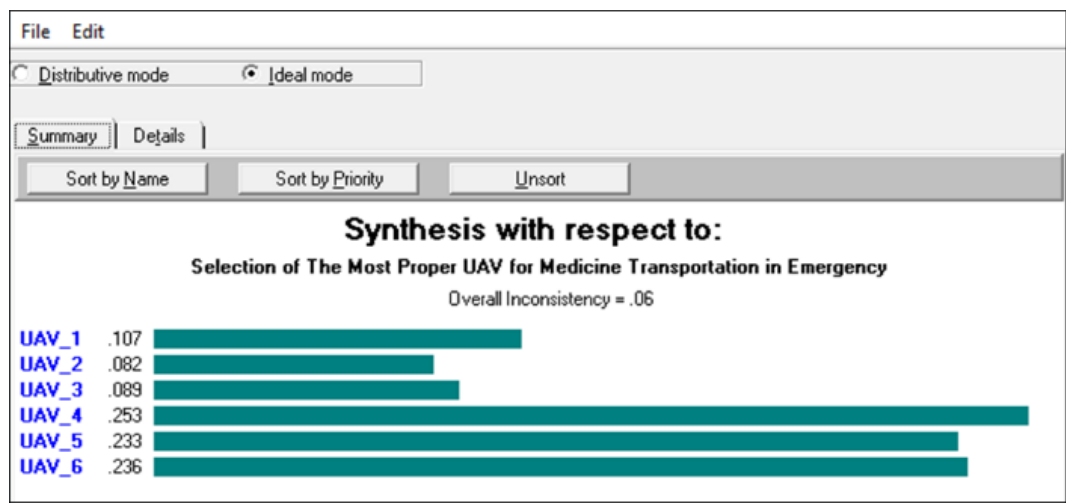

Figure 5. Overall Synthesized Weights by ExpertChoice for the Ideal Mode

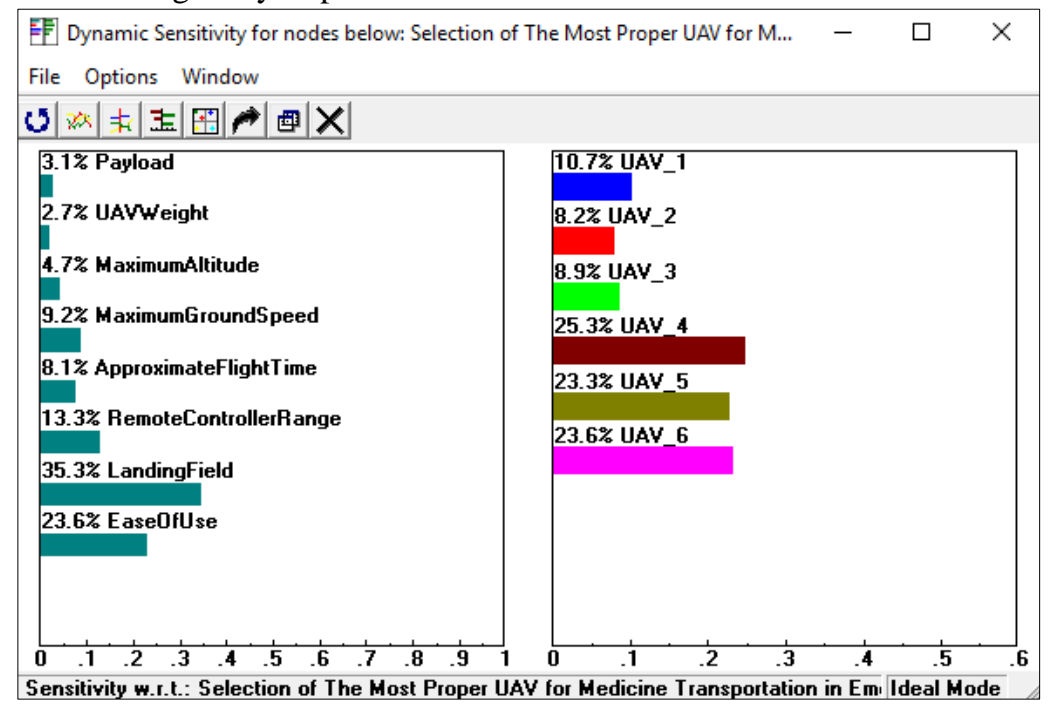

Figure 6. Weights by ExpertChoice for the Ideal Mode 
In a sensitivity analysis, it is aimed at having an opinion about how much the solution obtained through the AHP (The most proper UAV selection for medicine transportation in emergencies) is effective and robust, and understanding how it changes as the weights of each criterion changes for figuring out the most import factor in a solution, i.e. main effects. Figure 7 depicts the performance sensitivity analysis of the overall goal for each criterion.

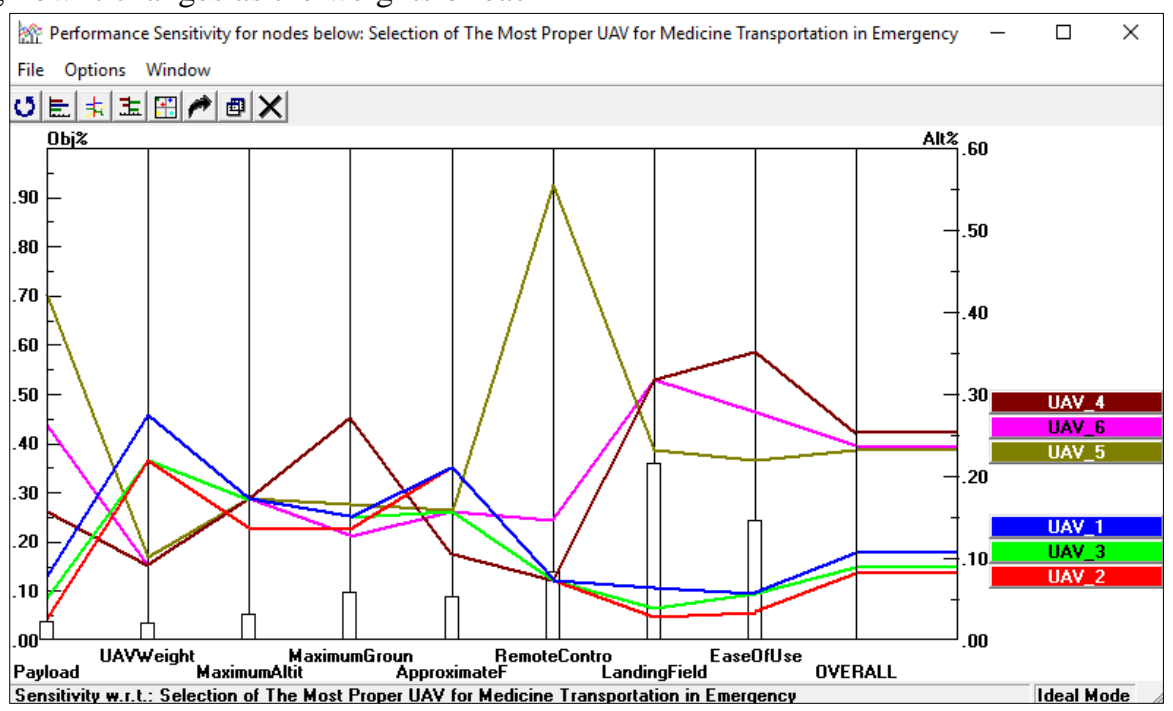

Figure 7. Performance Sensitivity Analysis according to Weights of Criteria

According to Figure 7, "UAV_4" with the highest global weight around 0.25 appears to be the best flight platform for medicine transportation in emergencies. UAV_2 has the lowest weight around 0.08, hence the least preferability. Moreover, while "landing field" is the most effective factor with its weight around 0.36 in the selection of UAV, "UAV weight" becomes the least effective criterion with its weight approaching 0.03 . Furthermore, increasing the weight of groundspeed and ease of use criteria favors UAV_4 the most; increasing the weights of maximum altitude and landing field favors UAV_6 the most; increasing the weights of

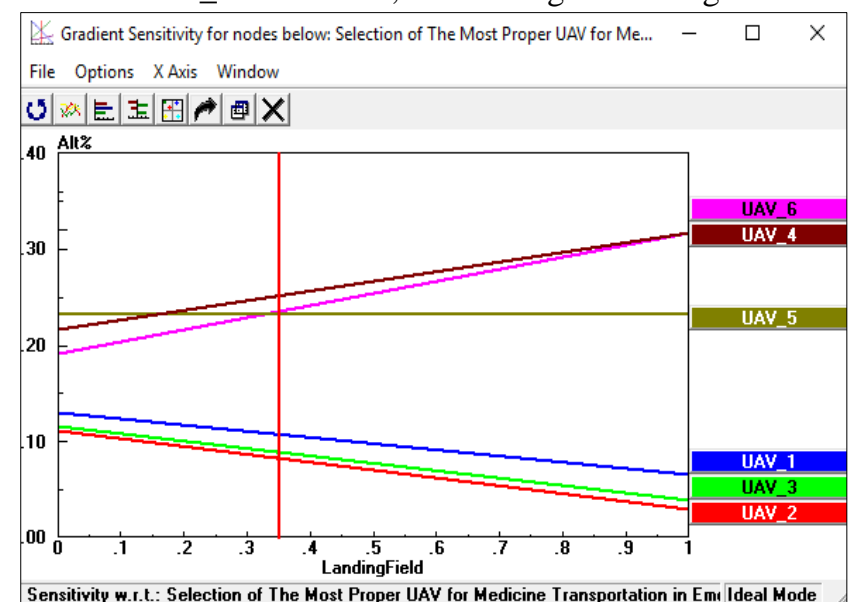

payload and remote-control range favors UAV_5 the most; increasing the weight of UAV weight and flight time favors UAV_1 the most.

The impact of changes in criteria's weights on alternatives' preferability order can be observed in detail through gradient analysis, which displays the break event points of criteria weights where the order of alternatives changes. Gradient analysis was performed for the most effective criteria such as landing field, ease of use, and remote controller range, and corresponding results were displayed in Figure 8a-c.

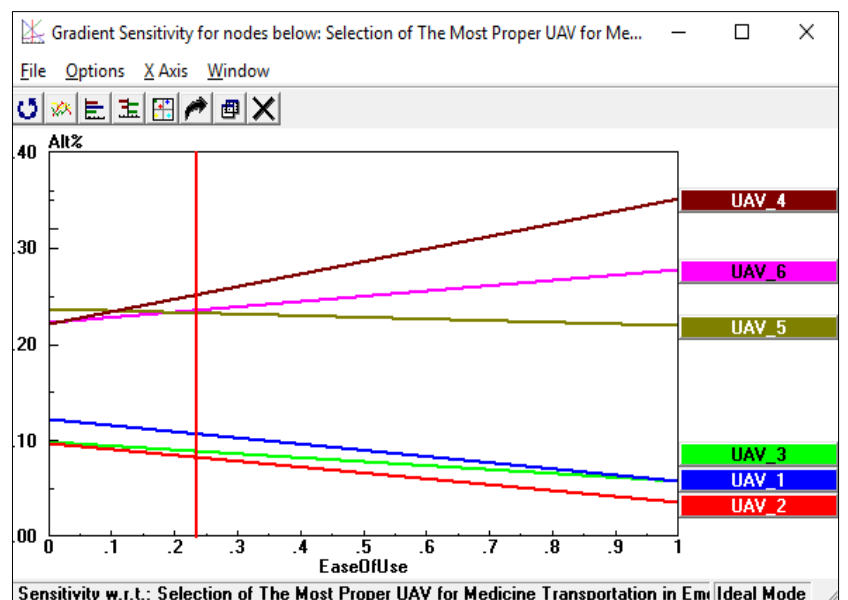
Figure 8. Gradient Sensitivity Analysis for Selected Criteria's Weights. 


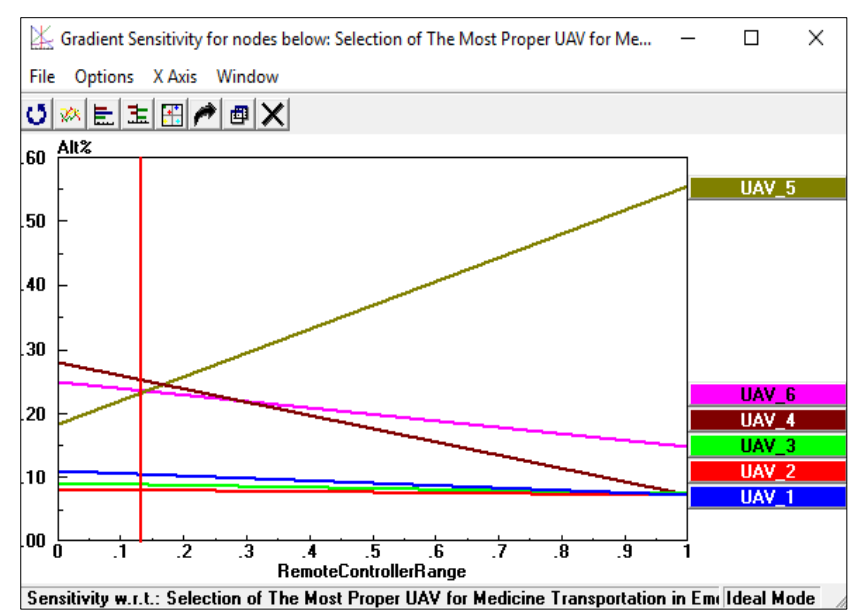

Figure 8. Cont.

A careful look at gradient graphs reveals that when the weight of the landing field falls below around 0.15, UAV_5 appears to be the best option (Figure 8a). Similarly, when the weight of ease of use criterion becomes less than around 0.1, UAV_5 appears to be the best selection (Figure 8b). As the weight of the remote controller range becomes more than around 0.18, UAV_5 turns to be the best option again (Figure 8c).
The pairwise comparison of alternatives where each criterion favors which alternative can be observed through head-to-head graphs of two alternatives in consideration. Pairwise head-to-head comparison graphs were prepared for multi-rotor UAVs whose global priority weights are very close to each other and results were presented in Figure 9a-c.

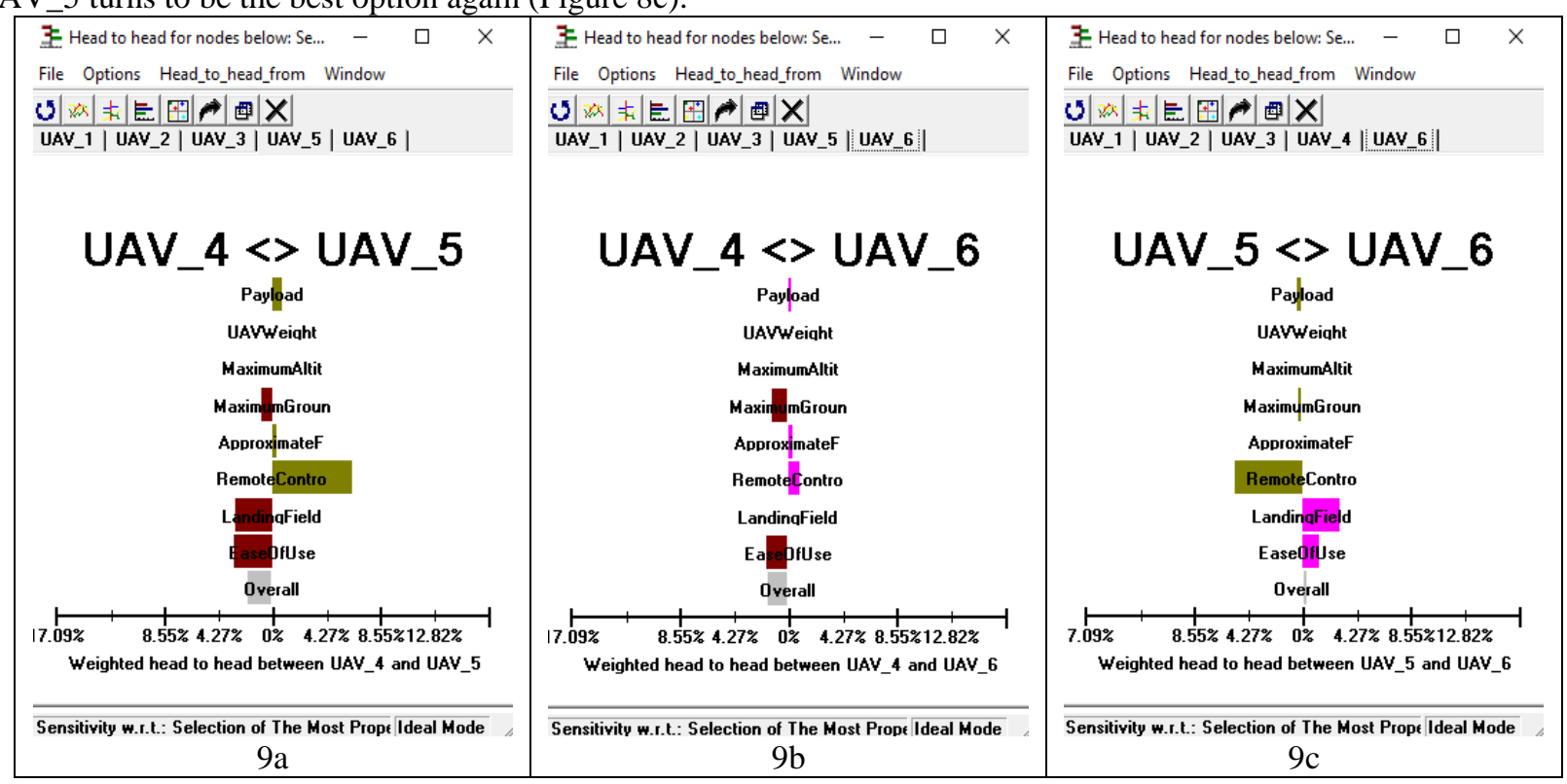

Figure 9. Head to Head Comparisons of Multi-rotor UAVs

When UAV_4 in the first rank is compared with 3rd rank alternative of UAV_5, it is revealed that payload, and approximate flight time criteria slightly, remote controller range criterion moderately favor UAV_5; maximum speed criterion slightly, landing field and ease of use criteria moderately favor UAV_4 (Figure 9a). Similarly, when the first rank selection alternative UAV_4 is compared with second rank selection alternative UAV_6, it is seen that payload, approximate flight time and remote controller range criteria slightly favor UAV_6 while maximum ground speed and ease of use criteria moderately favor UAV4 (Figure 9b). Finally, when the third rank selection of UAV_5 is compared to the second rank selection of UAV_6 in a head-to-head manner, it is observed that payload and maximum ground speed slightly, remote controller range criterion moderately favor UAV_5 while the ease of use criterion slightly and landing field moderately favor UAV_6 (Figure 9c). The above results can be obtained through 2-dimensional alternatives 2 comparison as well as illustrated in Figure 10. 


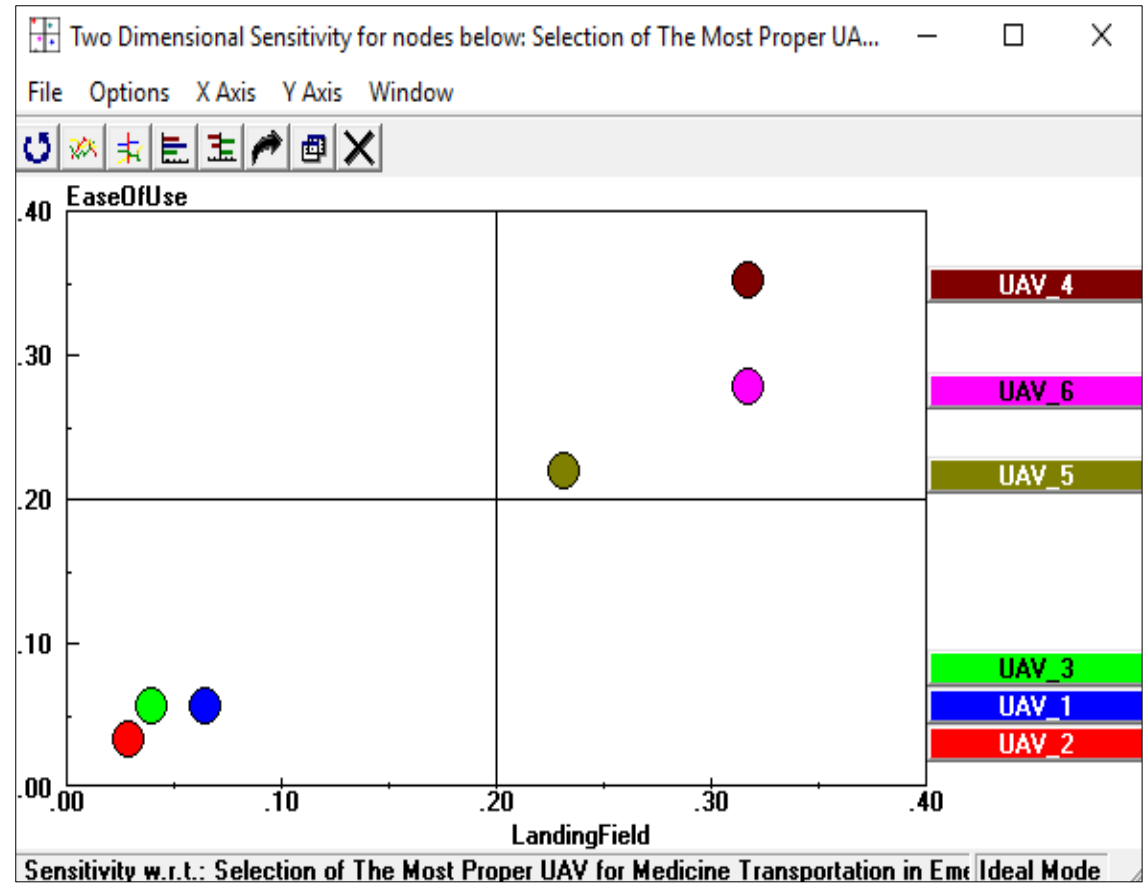

Figure 10. Two-Dimensional Analysis of Alternatives with respect to the Landing Field and the Ease of Use Criteria

As intuitively expected, the analysis of alternatives with respect to the landing field and ease of use criteria indicates that multi-rotor UAVs (UAV_4, UAV_5, UAV_6) dominate fixed-wing UAVs (UAV_1, UAV_2, UAV3). This is revealed from the 2-dimensional graph as multi-rotor alternatives located in top-right (first quarter) while fixed-wing alternatives are located in the left bottom (third quarter) on the graph constructed.

\section{Discussion and Conclusion}

In order to evaluate flight platforms, comparable performance indicators, and tests in more regions are required. In order to realize the use of UAVs in cargo transportation, statistics about the flights to be performed in the test areas, daily logs of the actual flights, climate information, failure rates, and other performance measurements of the flight platforms are needed. While most of the developing models are still in prototypes, along with the rapid developments experienced in recent years and the interest of the industry in this application, further progress can be expected in the coming years. The analytical hierarchy method used in this study takes into consideration not only quantitative data but also qualitative evaluation by experts in a novel way of dealing with the multi-criteria decision making of UAV selection problem. The sensitivity analysis conducted reveals how robust the final decision AHP provided. By this approach, one can easily adapt a decision of selection of proper UAVs depending on each criterion weight (i.e. importance).

The surveys in this area will gain beneficial results in satisfactory levels with multi-disciplinary practices that many disciplines will achieve. This study can be regarded as a pioneer to exploit the use of UAVs in a variety of settings one of which is emerging events.
Especially the methodology used (AHP) illustrates how expert opinion can be directly included in multi-criteria decision making related to UAVs. It also provides bases to improve the capabilities of UAVs to achieve a set of dedicated missions.

\section{Acknowledgments}

No grants have been received in this project. In this study, the authors used their own resources.

\section{References}

Al-Ahmari, A. M. A. (2008). A methodology for selection and evaluation of advanced manufacturing technologies. International Journal of Computer Integrated Manufacturing.

doi: 10.1080/09511920701678825

Al-Harbi, K. M. A. S. (2001). Application of the AHP in project management. International Journal of Project Management. doi: 10.1016/S0263-7863(99)00038-1

Bayırhan, İ., Gazioğlu, C. (2019). Use of Unmanned Aerial Vehicles (UAV) And Marine Environment Simulator in Oil Pollution Investigations, International Symposium on Applied Geoinformatics (ISAG-2019), Istanbul, TÜRKIYE, 7-9 Nov 2019, 16.

Bayırhan, İ., Gazioğlu, C. (2019). Use of Unmanned Aerial Vehicles (UAV) And Marine Environment Simulator in Oil Pollution Investigations, Baltic J. Modern Computing, 8, 327-336.

Clarke, R. (2014). Understanding the drone epidemic. Computer Law and Security Review. doi: 10.1016/j.clsr.2014.03.002

Colomina, I., Molina, P. (2014). Unmanned aerial systems for photogrammetry and remote sensing: A review. In ISPRS Journal of Photogrammetry and 
Remote Sensing. doi: 10.1016/j.isprsjprs.2014.02.013

Eisenbeiss, H. (2009). UAV Photogrammetry. Swiss Federal Institute of Technology Zurich.

Elkarmi, F., Mustafa, I. (1993). Increasing the utilization of solar energy technologies (SET) in Jordan. Analytic hierarchy process. Energy Policy. doi: 10.1016/0301-4215(93)90186-J

Enyinda, C. I. (2017). Quantitative Risk Analysis for International Project Management and Programs in an Emerging Economy. R. Benlamri \& M. Sparer (Eds.), Leadership, Innovation and Entrepreneurship as Driving Forces of the Global Economy (pp. 769780). Cham: Springer International Publishing.

Erenoglu, R., Erenoglu, O. (2018). A case study on the comparison of terrestrial methods and unmanned aerial vehicle technique in landslide surveys: Sarıcaeli landslide, Çanakkale, NW Turkey, International Journal of Environment and Geoinformatics, 5(3), 325-336, doi: 10.30897/ijegeo.468061.

FAA. (2016). United States Department of Transportation Federal Aviation Administration (FAA) Hand Book.

FSD. (2016). Drone in Humanitarian Action: A Guide to the Use of Airborne Systems in Humanitarian Crises. Swiss Foundation for Mine Action (FSD).

Hajeeh, M., Lairi, S. (2009). Marriage partner selection in Kuwait: An analytical hierarchy process approach. Journal of Mathematical Sociology. doi: 10.1080/00222500902953620

Hansen, R. L. (2016). Traffic monitoring using UAV Technology. American Surveyor.

Herwitz, S. R., Leung, J. G., Higgins, R. G., Dunagan, S. E. (2002). Remote command-and-control of imaging payloads using commercial off-the-shelf technology. IEEE International Geoscience and Remote Sensing Symposium, 5, 2726-2728 vol.5. doi: 10.1109/IGARSS.2002.1026755

Ishizaka, A., Labib, A. (2011). Review of the main developments in the analytic hierarchy process. In Expert Systems with Applications. doi: 10.1016/j.eswa.2011.04.143

Kablan, M. M. (2004). Decision support for energy conservation promotion: An analytic hierarchy process approach. Energy Policy. doi: 10.1016/S0301-4215(03)00078-8

Karataş, K., Altınışık, N. (2020). The Effect of UAV Usage on Detail Points in Cadastre Update Studies: Çorum-Karaköy Case Study. International Journal of Environment and Geoinformatics, 7(2), 140-146. doi.10.30897/ijegeo.646155.

Khorrami, B., Valizadeh Kamran, K., Roostaei, S. (2018). Assessment of Groundwater-Level Susceptibility to Degradation Based on Analytical Network Process (ANP). International Journal of Environment and Geoinformatics, 5(3), 314-324. doi. 10.30897/ijegeo.451067.

LEE, H. S. (2017). Priority Analysis of Subscription Attributes for High-Speed Internet Service: Application of AHP Technique. Journal of Internet Banking and Commerce, 22(1), 1-18.

Luege, T. (2016). Mapping Rapid Damage Assessments of Tabarre and Surrounding Communities in Haiti following Hurricane Sandy.

Mizrahi, S. (2017). A Framework for Strategic Performance Management for the Public Sector Using the Analytic Hierarchy Process. In Public Policy and Performance Management in Democratic Systems (pp. 99-126). Springer.

Ossadnik, W., Kaspar, R. (2013). Evaluation of AHP software from a management accounting perspective. Journal of Modelling in Management. doi: 10.1108/JM2-01-2011-0007

Saaty, T.L., Vargas, L. (2000). Fundamentals of Decision Making and Priority Theory With the Analytic Hierarchy Process. RWS Publications.

Saaty, T L. (2006). Rank from comparisons and from ratings in the analytic hierarchy/network processes. European Journal of Operational Research, 168(2), 557-570.

Saaty, Thomas L. (1988). The Analytic Hierarchy Process (Revised ed). Pittsburgh: The University of Pitssburgh.

Saaty, Thomas L. (1990). How to make a decision: The analytic hierarchy process. European Journal of Operational Research. doi: 10.1016/03772217(90)90057-I

Saaty, Thomas L. (2005). Theory and applications of analytic network process: decision making with benefits, opportunities, costs, and risks. Pittsburg: RWS Publications.

Schmidt, K., Aumann, I., Hollander, I., Damm, K., Von Der Schulenburg, J. M. G. (2015). Applying the Analytic Hierarchy Process in healthcare research: A systematic literature review and evaluation of reporting. In BMC Medical Informatics and Decision Making. doi: 10.1186/s12911-015-0234-7

Segui-Gasco, P., Al-Rihani, Y., Shin, H. S., Savvaris, A. (2014). A novel actuation concept for a multi rotor UAV. Journal of Intelligent and Robotic Systems: Theory and Applications. doi: 10.1007/s10846-0139987-3

Silvagni, M., Tonoli, A., Zenerino, E., Chiaberge, M. (2017). Multipurpose UAV for search and rescue operations in mountain avalanche events. In Geomatics, Natural Hazards and Risk. doi: 10.1080/19475705.2016.1238852

Stam, A., Duarte Silva, A. P. (2003). On multiplicative priority rating methods for the AHP. European Journal of Operational Research. doi: 10.1016/S0377-2217(02)00228-X

Thamm, H. P., Judex, M. (2006). The "low-cost drone"an interesting tool for process monitoring in a high spatial and temporal resolution. ISPRS Mid-Term Symposium, 8-11.

Tiwari, M. K., Banerjee, R. (2001). A decision support system for the selection of a casting process using analytic hierarchy process. Production Planning \& Control, 12(7), 689-694. doi: 10.1080/09537280010016783

Utlu, M., Öztürk, M., Şimşek, M. (2020). Rockfall Analysis Based on UAV Technology in Kazıklıali Gorge, Aladağlar (Taurus Mountains, Turkey). International Journal of Environment and Geoinformatics, 7(3), 239-251.doi. 10.30897/ijegeo.740963. 
van Blyenburgh, P. (1999). UAVs: an overview. Air \& Space Europe. doi: 10.1016/S1290-0958(00)88869-3

Waharte, S., Trigoni, N. (2010). Supporting search and rescue operations with UAVs. Proceedings - EST 2010 - 2010 International Conference on Emerging Security Technologies, ROBOSEC 2010 - Robots and Security, LAB-RS 2010 - Learning and Adaptive Behavior in Robotic Systems. doi: 10.1109/EST.2010.31

Zakarian, A., Kusiak, A. (1999). Forming teams: an analytical approach. IIE Transactions (Institute of Industrial Engineers). doi: 10.1080/07408179908969808. 